\title{
Response to \\ "Toward a Re-thinking of Mass Public Schooling: A Personal Exploration"
}

\section{Benjamin Levin}

OISE, University of Toronto

$\mathrm{T}$ HE ISSUES RAISED by LeRoy Whitehead are important and worth debating. Discussion of the forms of public education and the best way to organize provision of mass education is always needed as the social conditions around our schools change.

As I read it, Whitehead's essential argument is that our schools have significant problems, that these problems are strongly related to the basic organizational form of schools, and that we need to change this organizational form.

It's easy to agree that Canadian schools are imperfect and have problems, some of which are significant. As Tony Riffel and I wrote a decade ago (Levin \& Riffel, 1997), schools always face the challenge of responding to changing demographics, social norms and economic conditions and, like any large and complex organization, will struggle to do so effectively. Whitehead notes some issues; others would have different lists - for example the continued large gap between Aboriginal youth and other Canadians, or the challenges in supporting new immigrants, or the best ways to approach the burgeoning number of children who get identified as having disabilities.

On the other hand, there is nothing new about a claim that schools have problems. Criticisms of the failings of public education are as old as public education. Just read the analyses by Gerald Bracey or Richard Rothstein in the U S, with their collections of complaints about inadequate schools going back a century. Canada has its own similar history of complaints - for example Hilda Neatby's (1953) assault on the weaknesses of schooling in the 1950 s, made in what Whitehead regards as an easier, gentler era. Because we expect so much from our schools - to make every child perfect, essentially we will always be disappointed with the results at least to some degree. Of course we should continue to discuss and debate improvements, but nobody should have the illusion that there used to be a golden age when schools were problem free.

Moreover, one could just as easily put together a long list of positives about public education. Whitehead mentions some at the outset of his paper, such as the rather important point that more students are developing more skills than ever before. 
Canadian students rank highly in international comparisons. Our equity gap is smaller than in most other countries. Students with disabilities get a much better education than they did a generation ago. We are much more sensitive - even if still not enough to diversity issues. It's too easy to make a list of negatives; this is not a balanced view of the evidence. School systems always have problems - as do all other public institutions.

Some of Whitehead's presentation of problems is overstated. The public is hardly 'abandoning' public schools. Private school enrolments remain small in Canada; even in provinces which provide significant financial support, private schools still enroll only $5 \%$ or so of students and these numbers have not been growing significantly. There is scant evidence of a crisis in public education.

Whitehead seems to feel that lawsuits on educational matters are indicators of incivility. But laws provide an important, peaceful way to redress claims of wrong. Many important advances in education in Canada, such as in minority languages or in special education, are the result of litigation. Canada has relatively little litigation on educational matters, and the cases we do have often help clarify important issues.

Whitehead's key claim would seem to be this:

"Mass public schooling, as we know it, is a product (dare I say a relic?) of the industrial age and is becoming increasingly anachronistic in the post-industrial era." This claim has been made many times before. It is rooted in the Romantic tradition going back to Rousseau and Thoreau, and has been advocated by many other radical critics of education (remember Ivan Illich, anyone?). When I first got involved in education in the early 1970s we were in the midst of moving to 'non-graded schools' and 'open area classrooms' on the basis of views very similar to those stated here by Whitehead.

Whitehead's claim of standardization and specialization appears overstated. It is certainly true that schools embody elements of the industrial model, but schools are more than this. Schools across Canada do not have the same curriculum, or the same pedagogy or the same outcomes. Indeed, many critics of schooling decry the lack of these very same characteristics. One can continue to find large variations in teaching practices even within a given school let alone across districts or communities. Primary teachers continue to teach across all or most subjects. School boards continue to make important decisions about culture and program mix in their schools. Canada supports publicly a wide range of different kinds of schools. Canadian schools remain fairly small and are not, so far as I know, getting bigger on average. It seems a stretch to argue that our schools are a model of standardization.

Diversity in schooling is related to Whitehead's important point about goals. The reality is that people disagree about the goals of schooling. We want multiple and even inconsistent things from our schools. Some people want traditional instruction while others do not. Some want the teaching of particular values while others do not. Some want an emphasis on maths or science while others value the arts more. Some want integration of diverse students while others do not. Given these differences, any statement of goals - as most of those posted by districts or provinces - ends up being rhetorical, broad, vague, and essentially useless as a guide to practice. Disagreements on values - both in means and ends - cannot be overcome through goal-setting exercises. 
After all the critique, what does Whitehead propose? His point that education is not the same as schooling is evident in principle, buts its implications 'on the ground' are not so clear. He wants us to move to some kind of less bureaucratic and more organic form of education but says little or nothing about what this might actually mean in practice - as he writes, “...to move from age-based cohorts to some other system”. He seems to be in favour of non-compulsory schooling, and of having even more different kinds of schools. But everything depends on the specifics of change. It's easy to be in favour of an unspecified change, but any given change will have its own problems and limitations. More diverse schools with more local control could result in wider variations in quality and greater segregation of diverse populations. In an increasingly credentialed age, don't all students need access to the qualifications that gain entry to good jobs and a reasonable standard of living? In a diverse society it may be even more important to have at least some common elements in all schools.

As noted earlier, many attempts were made 30 years ago to implement some forms of what Whitehead seems to want. We had open area, multi-grading, continuous progress, more curriculum choice - or perhaps it would be more accurate to say more curriculum streams, since the choices were not always made by students. Almost all of this has long disappeared because either it did not work or people - read teachers, parents and students - did not support it.

By all means let us debate the quality, nature and future of our public schools. Such a debate is inherent in the very idea of public education. Yes, it is worth talking about the right ways to govern and organize our schools, and how to try to keep the focus on education rather than on the institution of schooling. Yet such a debate requires careful attention to a balance of evidence on the current situation, a historical understanding of what has gone before, and specific proposals as to how things might change for the better.

\section{References}

Levin, B. \& Riffel, J. (1997). Schools and the changing world. London, UK: Routledge. Neatby, H. (1953). So little for the mind. Toronto: Clarke Irwin. 


\section{The Author Replies...}

\section{LeRoy E. Whitehead}

Queen's University

Many students, especially those who are poor, intuitively know what the schools do for them. They school them to confuse process and substance. Once these become blurred, a new logic is assumed: the more treatment there is, the better the results; or, escalation leads to success. The pupil is thereby "schooled" to confuse teaching with learning, grade advancement with education, a diploma with competence, and fluency with the ability to say something new.

- Ivan Illich, Deschooling Society, p. 1.

$\mathrm{B}$ EN LEVIN SEEMS TO KNOW where I live so far as my intellectual journey has been concerned: yes, I do remember Ivan Illich. I liked what he had to say about the institutionalization of our society in De-schooling Society, and was especially drawn to his denunciation of credentialism. Some books are still worth re-reading years later.

I concede that I do often overstate my case for dramatic effect. Over 30 years of teaching graduate and undergraduate education students, it has been my experience that it often takes a dose of hyperbole to generate enough cognitive dissonance to get the complacent and uncritical ones in the group to engage in some critical analysis of the school system. In the present article, some of my metaphors (such as cracks in the fuselage) and some of the quotations preceding each section (the beached whale, perhaps) may be a bit over the top, but I believe a careful analysis of what I have actually said between these insertions of calculated color will show that my basic claims are really quite modest.

For example, I claimed only that the bureaucratic form of organization may be a contributor to, not the sole cause of, the dissatisfactions and dysfunctions that I perceive. And I did not claim that the schools are in crisis. I did say that there is evidence of dissatisfaction and dysfunction that could become disastrous. I did not allude to wholesale abandonment of the system, but to a small but growing number of families and individuals who are abandoning the system in favor of other options. On the other hand, however, if a school drop-out rate of almost 30 percent is not a crisis in a credentialed society, it must surely be at least crisis-like. Otherwise, why would the government bring out such a "sledgehammer" response? A 30 percent cull rate in an automobile factory or even a candy bar factory would certainly turn management heads and grab share-holder attention.

I did not say that litigation is an indication of incivility, or that it does not have useful functions. I did say that it is evidence of dissatisfaction and of increasing polarization in society, which I find very troubling. Ironically, much of this polarization is centered on the schools. So much for the schools bringing us together.

There is more standardization and synchronization in the system than Levin is willing to admit. It may be true that there are differences in the overt curriculum from 
province to province, for example, but the real standardization may be found in the organizational form and mode of operation, and in what we used to call, in the late 1960s and early 1970s, the "covert curriculum" - what the schools teach simply by the manner in which they are organized and conducted. The same concept goes by a different label now.

I did not say that the 1950 s were an easier, gentler era. I did say that the environment in which the schools operated then was more stable and that the clients of the system, the students, were more homogeneous as a group. Ease and gentleness have nothing to do with the theory of bureaucracy; stability and homogeneity have a lot to do with it.

Levin and I appear to be in agreement on several points: the issues raised are important and worth debating; Canadian schools have problems, some of which are significant; schools have never been problem-free; and there are many positive aspects to our schools, for example, students with disabilities get a much better education now than they did a generation ago.

We agree that there is currently no clear, publicly agreed-upon set of goals for our public school system. It is true that large, complex organizations may have complex, even conflicting goal sets. But we seem to part company at that point. I believe there must at least be a statement about what we are trying to do, and if we can't agree on even that much, then we have a system that is adrift without a framework for assessing every new educational fad or fashion that comes along, like open classrooms and nongraded schools. Make no mistake: governing parties, civil servants, teachers' unions, parents and students all have goal sets of their own for the system, stated or unstated. The very fact that one governing party may have different goals for the system than did the party that preceded it a few years previously, and that a new governing party after the next election may have yet different goals for the system is an important contributor to the shifting, unstable environment that makes the bureaucratic organizational form increasingly inappropriate for schools.

I think we would also agree that more local control of schooling would result in more variation, though I am not sure this necessarily would mean more variation in quality as Levin suggests. It really is not clear to me that we can define quality in education without first defining the goals of the enterprise.

The central core of my argument, which Levin seems to skirt around (or perhaps I have not made it adequately clear for the reader), is not simply that there are problems with the mass public school system and that we need to do something about it. As he points out, others have said this, and repeatedly so over a long period time. My argument is, I hope, a bit more subtle and potentially more constructive than that. My central argument is that the received theory of bureaucracy holds that a highly complex, bureaucratic organization will not function well in a situation characterized by a shifting, unpredictable environment and by a heterogeneous client base with many unique demands. I assert that our mass public school system is highly complex and bureaucratized and that it is now in such a situation as that just described vis-à-vis its environment and its clients. Therefore, according to the received theory, we should expect to observe dysfunction in the system. My catalogue of types of dissatisfactions 
and dysfunctions, along with examples of the same, is intended to demonstrate that the dysfunction predicted by the theory is, in fact, observed in the school system. These observations tend toward confirming bureaucratic theory as it relates to schools. The implications are (1) that until there is a change in the situation vis-à-vis the school environment and its clients, those who govern or manage the mass public school system should work toward a less bureaucratic rather than a more bureaucratic organizational form for the system, and (2) that they should not indulge their usual proclivity to resolve emerging problems with solutions that are ever more bureaucratic.

With regard to the attempted introduction of open classrooms and non-graded schools some years ago, these episodes are easily explained in light of organizational theory and change theory. In a nutshell, the school system was very complex and bureaucratic then, too. As the Mintzberg quote provided in the article points out, highly complex organizations resist innovation. In the case of the open classroom concept, school boards adopted the idea mainly because they thought it would save money on school construction (you didn't have to build so many interior walls), not necessarily because they were dedicated to the purported educational benefits of the concept. In the case of both open classrooms and non-graded schools, neither school boards nor provincial/state ministries of education were willing to spend the large sums of money that would have been required to provide fully adequate professional development programs for the teachers to enable them to develop the competence needed to implement these concepts. It was entirely predictable that the innovations wouldn't work under those circumstances.

Such innovations would fail today as well without adequate professional development. But with adequate professional development, such innovations would have a much more favorable outlook for success given the more advanced technological resources we now have available for individualizing instruction to the learner's pace. I refer, for example, to CDs, DVDs, cable and satellite television broadcasting, teleconferencing, computer technology including but not limited to on-line instructional programs, and pod-casting, not to mention old-fashioned books. What we still lack are political will, some astute change agents, and money for hardware and software as well as for adequate professional development for the teachers. I do not concede that my statement about the age-grade cohort being the shame of public education is an overstatement. The age-grade cohort system harms children.

It is true that my article did not provide much in the way of specific proposals for change. I do not apologize for that. I said at the outset that I would provide only the brief outline of an argument that has yet to be fully developed. One cannot re-design an entire school system with a single article. However, I did provide a general direction (less bureaucracy, not more) and some general principles (borrowed from the Tofflers) that could be used for assessing proposals for change.

I have truly enjoyed this exchange with Ben Levin. It has helped to further clarify my thinking, for which I am grateful. I expect to continue working on these ideas, and will welcome thoughtful comments, references to useful studies and publications, and constructive criticism from colleagues and readers with similar areas of interest. Please contact me by e-mail at whitehea@queensu.ca. 